\title{
Erratum to: Polar localization of MreB actin is inhibited by anionic phospholipids in the rod-shaped bacterium Escherichia coli
}

\author{
Daisuke Shiomi $^{1}$ (D)
}

Published online: 10 May 2017

(C) Springer-Verlag Berlin Heidelberg 2017

\section{Erratum to: Curr Genet \\ DOI: 10.1007/s00294-017-0696-5}

In the original publication, the description of the conservation of MreB in bacteria was incorrect (the first paragraph of Introduction). The accurate description of the conservation of MreB is that "MreB is conserved mainly in rodshaped bacteria (Jones et al. 2001; Daniel and Errington 2003). Recent study revealed that MreB is also present in a coccoid bacterium Chlamydia which lacks FtsZ required for cell division in most bacteria although MreB in this bacterium plays a role in cell division (Ouellette et al. 2012)". The following reference should be added.

Ouellette SP, Karimova G, Subtil A, Ladant D (2012) Chlamydia co-opts the rod shape-determining proteins MreB and Pbp2 for cell division. Mol Microbiol 85:164178. doi:10.1111/j.1365-2958.2012.08100.x

The online version of the original article can be found under doi:10.1007/s00294-017-0696-5.

Daisuke Shiomi

dshiomi@ rikkyo.ac.jp

1 Department of Life Science, College of Science, Rikkyo

University, 3-34-1 Nishi Ikebukuro, Toshima-ku,

Tokyo 171-8501, Japan 